\title{
Fibromuscular dysplasia: its various phenotypes in everyday practice in 2021
}

\author{
Patricia Van der Niepen ${ }^{1}$, Tom Robberechts', Hannes Devos², Frank van Tussenbroek², Andrzej Januszewicz³, \\ Alexandre Persu ${ }^{4}$
}

'Department of Nephrology and Hypertension, Universitair Ziekenhuis Brussel, Vrije Universiteit Brussel, Brussels, Belgium 2Department of Radiology, Universitair Ziekenhuis Brussel, Vrije Universiteit Brussel, Brussels, Belgium

${ }^{3}$ Department of Hypertension, National Institute of Cardiology, Warszawa, Poland

${ }^{4}$ Pole of Cardiovascular Research, Institut de Recherche Expérimentale et Clinique and Division of Cardiology, Cliniques Universitaires Saint-Luc, Université Catholique de Louvain, Brussels, Belgium

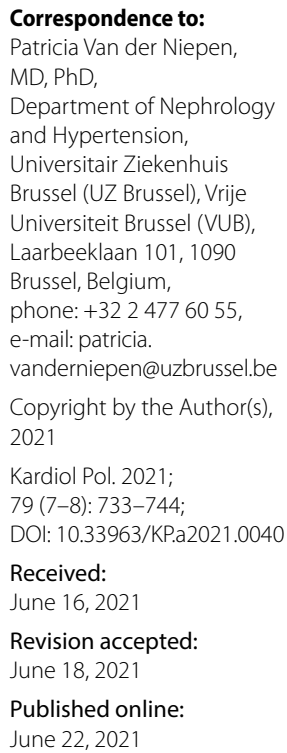

\section{A B S T R A C T}

Fibromuscular dysplasia (FMD) is a non-atherosclerotic vascular disease that may involve medium-sized muscular arteries throughout the body. The pathogenesis of FMD remains poorly understood, but a combination of genetic and environmental factors may be involved. The majority of FMD patients are women, but men may have a more progressive disease, especially when smoking. Besides the classical phenotype of string of beads or focal stenosis, arterial aneurysms, dissections, and tortuosity are frequent manifestations of the disease. However, the differential diagnosis of FMD is extensive and includes imaging artefacts as well as other arterial diseases. Diagnosis is based on CT-, MR-, or conventional catheter-based angiography during work-up of clinical manifestations, but clinically silent lesions may be found incidentally. Arterial hypertension and neurological symptoms are the most frequent clinical presentations, as renal and cerebrovascular arteries are the most commonly involved. However, involvement of most arteries throughout the body has been reported, resulting in a variety of clinical symptoms. The management of FMD depends on the vascular phenotype as well on the clinical picture. Ongoing FMD-related research will elaborate in depth the current progress in improved understandings of the disease's clinical manifestations, epidemiology, natural history and pathogenesis. This review is focused on the clinical management of adult FMD in daily practice.

Key words: carotid artery dissection, fibromuscular dysplasia, renal artery stenosis, spontaneous coronary artery dissection, visceral FMD

Kardiol Pol 2021; 79, 7-8: 733-744

\section{INTRODUCTION}

Fibromuscular dysplasia (FMD) is an idiopathic, segmental, non-atherosclerotic and non-inflammatory disease of medium-sized muscular arteries, leading to stenosis [1-3]. Two types of angiographic appearance exist (Figure 1A-C): (1) multifocal (MF) FMD, alternating areas of stenosis and dilation (the so-called 'string of beads'), which usually occurs in the mid and distal portions of the artery; or (2) focal (F) FMD, which may occur in any part of the artery [1, $4,5]$. Aneurysms, dissections, and arterial tortuosity are also frequent manifestations of the disease, but these lesions can only be attributed to FMD in the presence of a typical string-of-beads or focal stenosis, as these lesions have been described in other vascular diseases as well [3,6-8]. Renal and cerebrovascular arteries are most frequently involved, but all other medium-sized arteries may be affected [3, 9-14]. Involvement of $>1$ vascular bed, i.e., multivessel FMD, is seen in a substantial proportion of patients, ranging from $30 \%$ to $57 \%[3,9-13,15]$.

The prevalence of FMD in the general population is unknown because this disease is often clinically silent. FMD may be diagnosed during work-up of clinical symptoms and/or signs, but can also be discovered incidentally during imaging tests performed for other reasons $[3,16]$. The clinical manifestations of FMD depend on the vascular beds involved and the vascular phenotype. FMD may be asymptomatic, as well as be at the origin of severe or even life-threatening complications [13]. The diagnosis of FMD also requires exclusion of other vascular diseases, such as atherosclerosis, monogenic (e.g., Ehlers Danlos type 4) and 
inflammatory arterial diseases (e.g., large vessel vasculitis), as well as imaging abnormalities/artefacts (e.g. arterial spasm, standing waves) [3].

Diagnosis is made by imaging, i.e., duplex ultrasound, computed tomography (CT) or magnetic resonance (MR) angiography, while catheter-based arteriography remains the gold standard [3].

Management of FMD depends on the clinical presentation and the arterial lesion(s). Medical therapy with or without revascularization (endovascular or surgical) may be needed. However, clinical trials evaluating the efficacy of medical therapy with or without intervention are lacking.

As FMD is a chronic arterial disease, long-term follow-up is recommended. The frequency of follow-up will largely depend on the clinical presentation, but at least annual follow-up is advised by the international consensus [3]. Follow-up includes a clinical and physical examination, reviewing adherence to medical therapy, blood chemistries (e.g., renal function, electrolytes, lipids, and glucose), and urinalysis for albuminuria. Imaging follow-up, should be customized to each patient based upon the nature, extent and severity of arterial lesions and severity or recurrence of symptoms. Patients who have undergone revascularization procedures may require more frequent imaging surveillance [3]. Pregnant women with FMD also require more intensive follow-up, especially those with renal FMD because of an increased risk of gestational hypertension, preterm birth and, to a lesser extent preeclampsia, and those with known aneurysms, because of increased rupture risk $[3,17,18]$.

Recent prospective registries and ongoing research have substantially improved our knowledge and understanding of the disease's clinical manifestations, epidemiology, natural history, and genetics [9-12, 19]. FMD is no longer considered a rare cause of renovascular hypertension in young women, but rather appears as a systemic arterial disease, which may occur in both sexes at any age and with a wide range of manifestations. Yet, while up to $90 \%$ of patients with FMD are women, men have a more aggressive course with a higher frequency of aneurysms and dissections $[9,11,20]$. The pathogenesis remains poorly understood, although a combination of genetic (particularly the PHACTR1 variant), mechanical, hormonal, and environmental factors, such as smoking, may play a role [21-23].

\section{RENAL FMD}

The typical clinical presentation of renal FMD is a young to middle-aged Caucasian woman with arterial hypertension $[9-12,15]$. While the prevalence of FMD in the general population is unknown, studies from living kidney donor candidates indicate a prevalence of renal FMD of about 3.3\% [24]. The prevalence of renal FMD among patients with hypertension enrolled in the Cardiovascular Outcomes in Renal Atherosclerotic Lesions (CORAL) trial was $5.8 \%[25,26]$. Among subjects with FMD in the US,
European and ARCADIA registries, the renal arteries were involved in $66 \%-91 \%$ of patients [9-12, 15, 19]. The majority of these patients have a multifocal type of FMD (up to $95 \%$ ) and multivessel involvement (up to $57 \%$ ) [9-12, 19] (Figure 1). Patients with focal and multifocal lesions differ in age at diagnosis of FMD (30 years vs 49 years), in age at diagnosis of hypertension ( 26 vs 40 years), in sex distribution (female to male ratio, 2:1 vs 5:1), in initial blood pressure $(157 / 97 \mathrm{~mm} \mathrm{Hg}$ vs $146 / 88 \mathrm{~mm} \mathrm{Hg})$, in current smoking ( $50 \%$ vs $26 \%$ ), in prevalence of unilateral renal artery lesions (79\% vs 38\%), in presence of kidney asymmetry ( $33 \%$ vs $10 \%$ ), in renal revascularization procedures $(90 \%$ vs $35 \%)$, and in hypertension cure rates in patients who underwent revascularization (54\% vs $26 \%$ ) $[5,9]$. Besides multifocal and focal stenotic lesions, renal FMD may present as aneurysms and/or dissections (Figure 1D). Recently it was shown in 72 patients with renal infarction related to renal artery dissection (RAD) that FMD was the third main cause of spontaneous RAD. New onset RAD occurred in $25 \%$ of these patients with FMD, while de novo extra-renal dissection was present in only $6.3 \%$ after a follow-up of 51 months [27]. Renal artery dissection may be asymptomatic or present with distal thromboembolic events (e.g., renal infarct). Renal infarction, often related to underlying dissection, may be an initial manifestation of renal FMD $[28,29]$.

\section{Diagnosis}

In case of suspicion of renal FMD, the international consensus recommends performing a computed tomographic angiography (CTA) as the first step to confirm the diagnosis. A contrast-enhanced magnetic resonance angiography (MRA) is an alternative if CTA is contraindicated. CTA however has a better spatial resolution and visualizes small calcifications better, thereby providing a more accurate discrimination of FMD from atherosclerotic renal artery stenosis. Duplex ultrasound as the first diagnostic test for renal FMD should only be considered in specialized centers with extensive experience in duplex ultrasound for evaluation of FMD [3].

Although catheter-based angiography is the gold standard for imaging the location and morphology of FMD, it is indicated only when its findings are expected to affect patient management, or when a high clinical suspicion persists despite negative findings on CTA or MRA. In patients with MF renal artery FMD, imaging alone does not allow determining the severity and hemodynamic significance of renal artery stenosis as renal blood flow and plasma renin are often normal [30]. Therefore, translesional pressure gradient measurement is recommended by the international consensus in order to assess the hemodynamic significance of stenosis, as well as post-angioplasty to ensure the pressure gradient has been obliterated. In experienced centers, the procedure may be combined with intravascular ultrasound or optical coherence tomography [3]. 

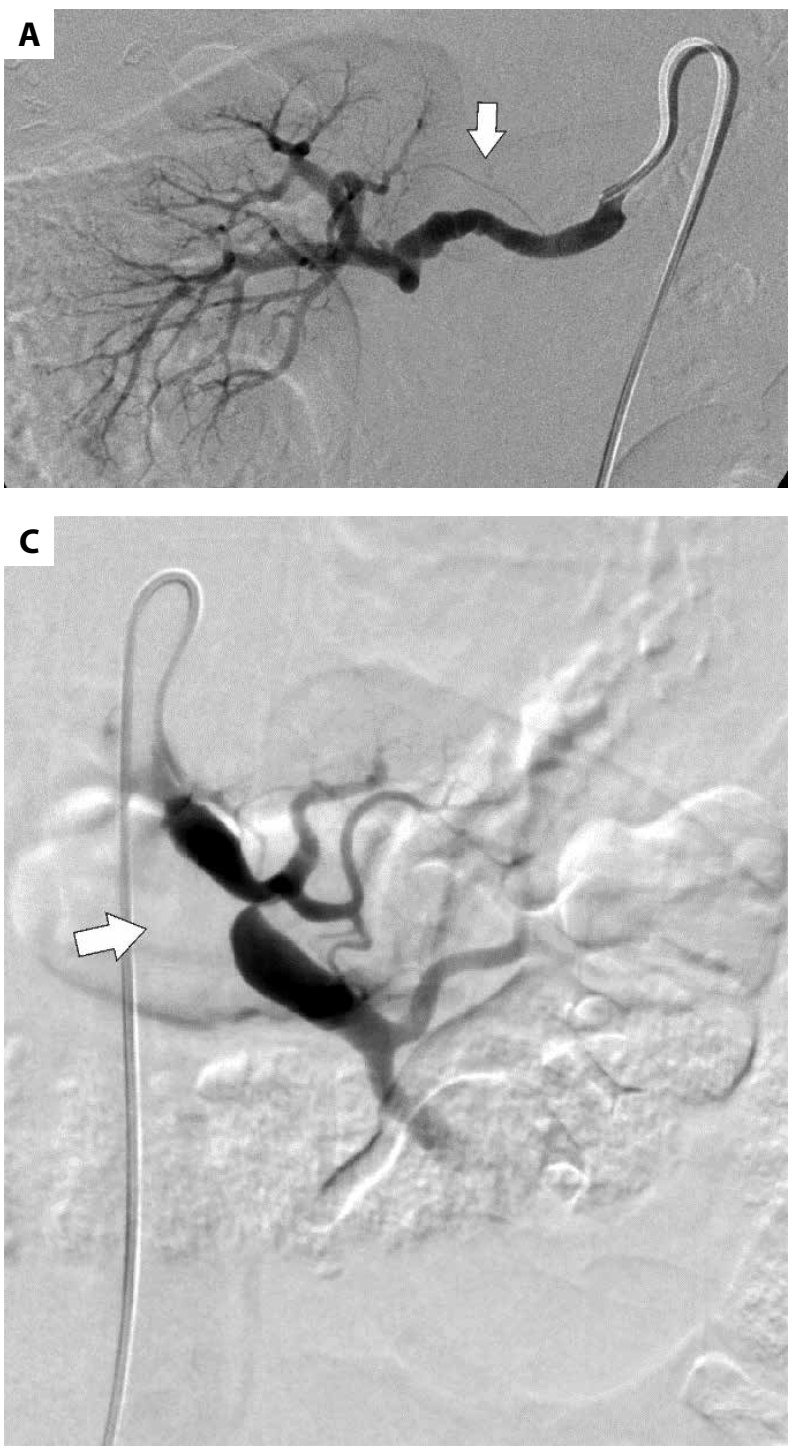

Figure 1. A. Multifocal fibromuscular dysplasia (MF-FMD) of the right renal artery in a 68-year-old woman with FMD lesions in both renal and common iliac arteries, and tortuosity of both vertebral and common carotid arteries. B. Focal (tubular) FMD in a 51-year-old man with hypertension. C. Focal (unifocal) FMD in a 33-year-old man with hypertension. D. Renal aneurysm in a 33-year-old woman with cervical MF-FMD

\section{Treatment}

Hemodynamically significant renal FMD (translesional pressure gradient $\geq 10 \%$ ) should be treated with angioplasty without stenting, as stent kinking and fracture have been reported in the setting of renal FMD [3, 31-33]. Revascularization with stenting is reserved for the treatment of procedural complications, such as a dissection or arterial rupture. Repeat angioplasty can be attempted following primary failure of angioplasty or recurrent stenosis; however, multiple procedures are not recommended to avoid jeopardizing future surgery [3]. Surgery is recommended following failure of angioplasty and remains the primary approach in patients with complex FMD lesions of the
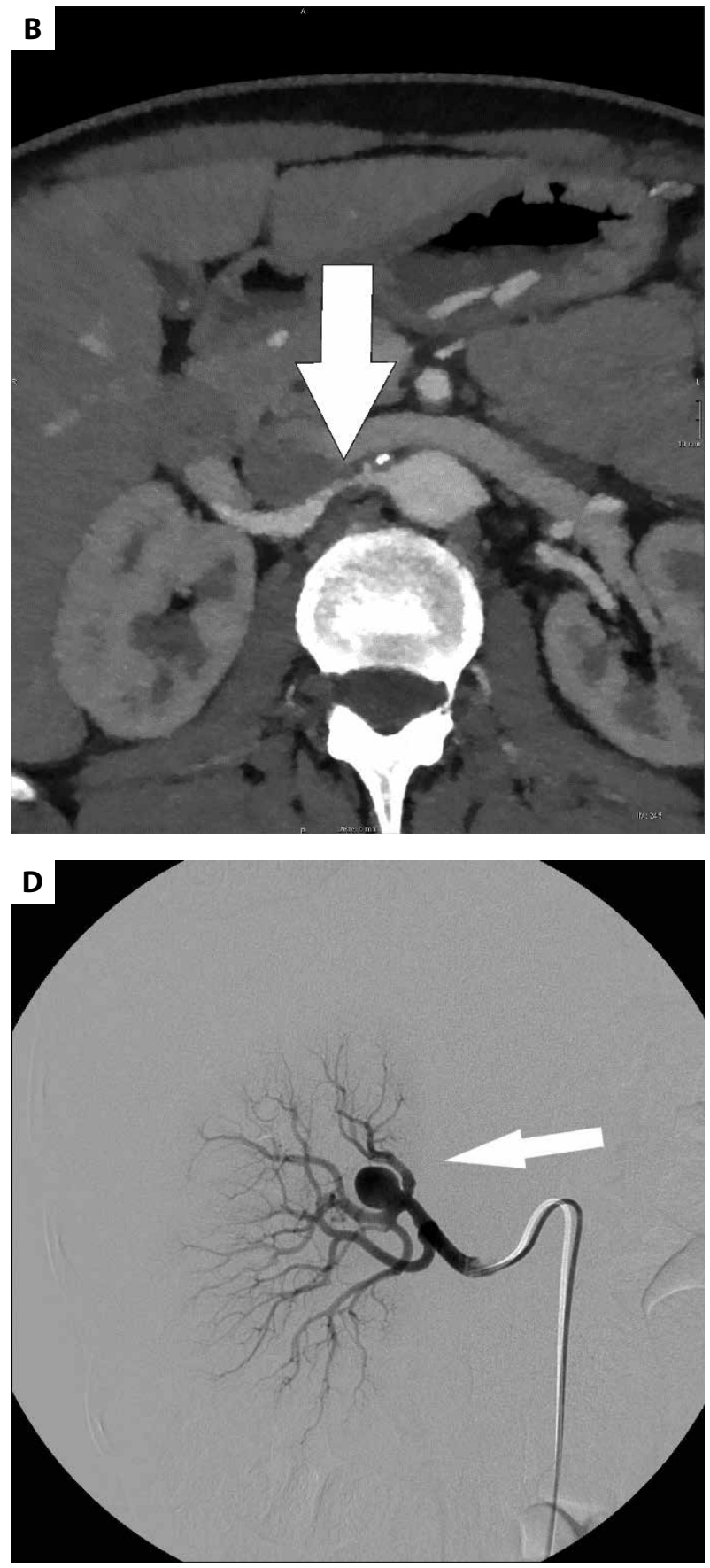

arterial bifurcation or branches, and stenosis associated with complex aneurysms [34]. Endovascular treatment with covered stent or coil embolization, or surgery are also needed if a renal artery dissection is progressive or causes renal hypoperfusion or a secondary aneurysm develops. Intervention for renal artery aneurysms (RAA) in the general population is performed for all symptomatic aneurysms and if the size exceeds $2 \mathrm{~cm}$. However, RAAs tend to have a benign natural history with extremely low rupture rates and slow growth rates in the general population [35]. Specific data for RAA in FMD are lacking. In pregnant women or women of childbearing age an aneurysm of any diameter is considered to be an absolute indication for elective repair, 
considering the risk of rupture with associated high fetal and maternal mortality [36]. Potential procedures to treat aneurysms include coiling, covered stents, or surgery (i.e., resection and/or bypass). Procedures should be avoided if an occluded aneurysm is detected, or if treatment may sacrifice vital organ parenchyma [37-40].

Outcomes following revascularization for renal FMD have been variable $[5,41,42]$. This may partly result from the difficulty to estimate the hemodynamic significance of a stenotic lesion with the different noninvasive and invasive imaging methods [43-45]. In a meta-analysis by Trinquart et al. [41], the rate of cure of hypertension (defined as blood pressure $<140 / 90 \mathrm{~mm} \mathrm{Hg}$ without medication) ranged between $14 \%$ and $85 \%$ after angioplasty across 11 clinical studies. The probability of being cured was associated with younger patient age at the time of treatment and shorter duration of hypertension. A repeat procedure was performed in $18 \%$ of the patients. In addition, the presence of a higher serum creatinine ( $1.45 \mathrm{mg} / \mathrm{dl}$ vs $0.82 \mathrm{mg} / \mathrm{dl})$ and a high-normal renal resistive index ( 0.74 vs 0.59 ) may jeopardize cure after angioplasty [46]. Savard et al. [5] reported that F-FMD was associated with a higher hypertension cure rate after angioplasty than MF-FMD.

Recurrence of stenosis after percutaneous transluminal renal angioplasty (PTRA) may occur in a short time, especially in F-FMD. Therefore, the International Consensus recommends follow-up with renal duplex ultrasonography (DUS) every 6 months for 2 years to detect restenosis [3]. Patients with MF-FMD might require a less frequent follow-up, however lifelong follow-up is advised as restenosis can occur much later. In a recent cross-sectional study of 26 patients with FMD (15 F-FMD, 11 MF-FMD), Oribe et al. [47] showed that these two angiographic types of FMD have indeed a different clinical course. In addition, patients with MF-FMD and with a younger age of onset may not only present with restenosis but also with de novo stenosis at different segments of the renal arteries, justifying long-term follow-up (>10 years).

The treatment of hypertension in patients with renal FMD, regardless of whether or not revascularization is performed, follows the international guidelines for the management of high blood pressure $[48,49]$. All antihypertensive medications can be prescribed in renovascular hypertension, although angiotensin converting enzyme inhibitors or angiotensin receptor blockers are preferable in this setting.

Despite the absence of placebo-controlled studies of antiplatelet therapy for FMD the use of antiplatelet agents (low dose aspirin, 75-100 mg daily) is recommended by the international consensus for both symptomatic and asymptomatic patients with FMD in view of the theoretical risk of thrombotic and thromboembolic events [3]. Indeed, turbulent flow due to multifocal FMD, marked arterial tortuosity, and other FMD-related lesions may cause platelet aggregation [3]. However, the benefits and potential risks of long-term low dose aspirin treatment should be weighed on an individual basis.

After PTRA, short-term (e.g., 4-8 weeks) dual antiplatelet therapy and long-term low dose aspirin are justified. If a renal artery dissection - with or without renal infarction - occurs, short-term anticoagulation or dual antiplatelet therapy (e.g., 3-6 months) followed by long-term antiplatelet therapy is recommended [3]. During follow-up visits post revascularization antihypertensive and antiplatelet therapy has to be reassessed.

The treatment of hyperlipidemia follows the current European Society of Cardiology/ European Atherosclerosis Society (ESC/EAS) guidelines, as there are no data to support the use of statins in patients with FMD without hypercholesterolemia [50].

Smoking cessation should be strongly encouraged for all patients with FMD. Besides the known health-related benefits in the general population, patients with FMD who smoke reportedly have a more progressive and severe disease than non-smokers [22, 23]. However, this association was not confirmed in the ARCADIA-POL study [51].

\section{CEREBROVASCULAR FMD}

Systematic imaging of all arterial beds beyond the initial site of diagnosis has revealed lower to similar frequency of involvement of cervical (24.6\%-80.4\%) compared to renal $(66.1 \%-90.7 \%)$ artery disease $[3,9-12,15,16,19]$.

Headache (especially migraine), pulsatile tinnitus, dizziness, or light-headedness are non-specific symptoms that may be the consequence of cerebrovascular FMD. However, patients can be asymptomatic or may present with focal neurological deficits, such as transient ischemic attack or stroke $[3,4,9,52-56]$. In case of cervical artery dissection (ceAD), these focal neurological symptoms may be accompanied by neck, face, or head pain [6].

FMD-related cerebrovascular lesions include carotid and vertebral artery stenosis, arterial dissection, and aneurysm formation (Figure 2). Multifocal FMD is the most common phenotype and typically affects the mid-distal portion of the internal carotid or vertebral arteries at the level of the C1 and C2 vertebrae, a location often spared by atherosclerosis. The majority of cervical FMD cases involve the internal carotid artery, often bilaterally, while vertebral artery involvement is less common and often coexists with carotid FMD. Intracranial FMD is rare and typically co-occurring with extracranial FMD. An unruptured aneurysm (Figure $2 \mathrm{C}$ ) is often the primary manifestation of intracranial FMD $[53,54]$. These aneurysms are more often found in a high-risk location (posterior circulation) and are of larger size than non-FMD related aneurysms [57]. The prevalence of intracranial aneurysms is also significantly higher than in the general population [6,57]. Therefore, and because of the risk of rupture, brain screening with CTA or MRA is recommended for all patients with confirmed FMD in any location [3]. The risk of rupture depends on aneurysm-re- 

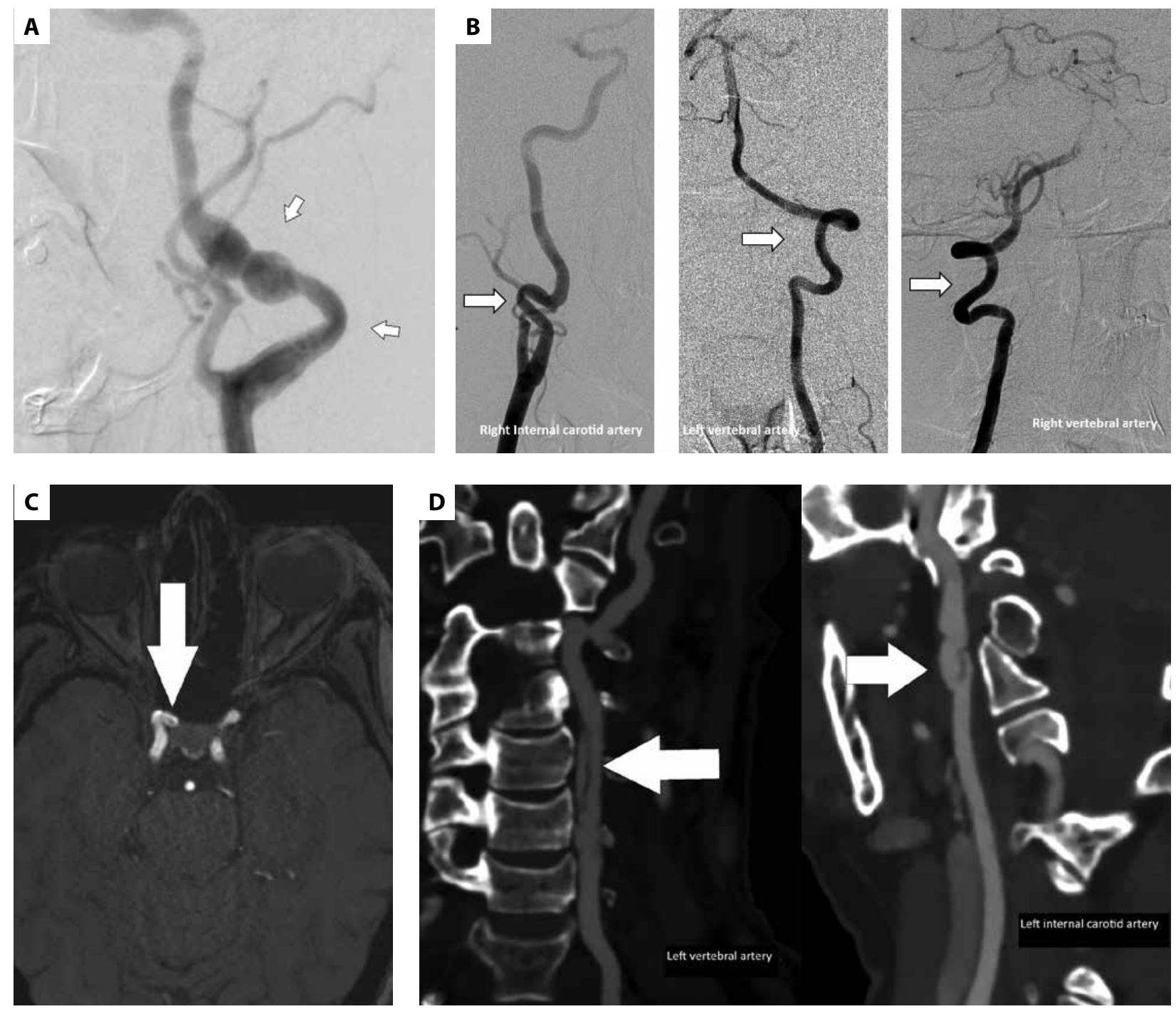

Figure 2. A. Multifocal fibromuscular dysplasia (MF-FMD) of both carotid arteries with aneurysmal dilatation in a 48-year-old woman with bilateral MF-FMD of the renal and common iliac arteries. B. Tortuosity of carotid and vertebral arteries in a 68-year-old woman with MF-FMD of both renal and common iliac arteries. C. Small saccular aneurysm of the right cavernosal internal carotid artery in a 46-year-old woman with bilateral MF-FMD of the renal arteries. D. Dissection of the left internal carotid artery and left vertebral artery post partum in a 33-year-old woman

lated factors (size and growth, irregular shape, and location of aneurysms), and patient modifiable and nonmodifiable characteristics (arterial hypertension, smoking, alcohol use, patient age [ $\geq 70$ years], geographical region, i.e., Japan, Finland, prior history of rupture, female sex, multiple intracranial aneurysms, family history of $\geq 2$ relatives with unruptured intracranial aneurysms or subarachnoidal hemorrhage) [58]. Whether the risk of rupture of intracranial aneurysms is higher in patients with FMD than in the general population ( $<1 \%$ per year) remains uncertain $[53,57]$.

Cervical (carotid or vertebral) artery dissection is a frequent event of FMD (Figure 2D). The prevalence varies between $9 \%$ and $39.5 \%$, and is highest among patients with a neurological presentation leading to diagnosis of FMD $[6,10,11,16,53,59,60]$. In the US FMD registry, the prevalence of carotid artery dissection is 3 to 4 times higher than vertebral artery dissection $[6,10]$. Multiple ceADs are frequent in patients with FMD and the prevalence is esti- mated to be up to $37 \%[6,10]$. In patients with ceAD, the overall prevalence of cervical FMD ranges between $8 \%$ to $20 \%$, and the diagnosis of FMD is more frequently reported in patients with multiple and recurrent ceAD [11, 61-63].

Several factors, including younger age, migraine (especially migraine without aura), mechanical trigger events, and infections have been reported to be associated with ceAD [64]. In the ARCADIA (Assessment of Renal and Cervical Artery Dysplasia) registry, male sex, age $<50$ years, history of migraine, and involvement of $\geq 3$ vascular beds are also reported as independent risk factors for ceAD in FMD, while fewer patients had a history of hypertension [60].

Recent data from the IPSYS (Italian Project on Stroke at Young Age) ceAD study showed a different risk factor profile between ceAD patients with and without cervical FMD (ceFMD). A history of migraine, the presence of intracranial aneurysms, and the occurrence of minor traumas before the event were associated with ceFMD [65]. However, no 
differences in clinical characteristics between patients with ceAD and FMD and those without FMD were observed in the ARCADIA-POL registry [59].

Recurrence rate of ceAD is rather low. Of 147 known ceFMD patients, of whom 52 had an aneurysm and another 52 a dissection, only 3 patients (5.8\%) experienced a new dissection and none of the patients developed a new aneurysm after a mean follow-up of 35.3 months [66]. The prevalence of recurrent ceAD was also low (3.3\% after a median follow-up of 34 months) in the IPSYS ceAD study. Having FMD and migraine were independent predictors of ceAD recurrence [65].

\section{Diagnosis}

CTA or contrast-enhanced MRA has replaced catheter-based angiography as the initial imaging modality. The latter remains the diagnostic gold standard, but its use is reserved for complicated cases that require intervention (repair of an aneurysm or pseudoaneurysm related to dissection, or severe stenotic lesions causing focal neurological symptoms). In experienced centers, vascular DUS can be used in the evaluation of carotid FMD; however, distal carotid lesions may escape DUS. Furthermore, it is inadequate to assess vertebral and intracranial arteries. Carotid DUS may be useful for follow-up of carotid artery $\operatorname{FMD}[1,3,4]$.

\section{Treatment}

Asymptomatic carotid or vertebral string of beads, even severe are not an indication of revascularization [3].

The treatment of migraine in patients with FMD follows the same approach as in patients without FMD and may include lifestyle modification to avoid triggering factors, preventive therapies, and medications to halt migraines. However, vasoconstrictive agents should be avoided, especially in patients with a history of ceAD [67].

The approach to pulsatile tinnitus in patients with FMD may include sound or cognitive behavioral therapy besides reassurance. Consultation with an otolaryngologist is advised to evaluate hearing and to assess for other causes of tinnitus beyond FMD $[3,68]$. Preventive aneurysm exclusion can be performed by surgical clipping or endovascular coiling with or without additional insertion of regular or flow-diverting stents. The choice of the treatment modality depends on anatomical factors and the assessment of the neurointerventionalist, and, in the absence of specific evidence, does not differ from that of patients without FMD. In patients with low rupture risk aneurysms, or high risk of preventive repair-related complications, or if patients prefer conservative therapy, observation with follow-up imaging to detect growth or change in morphology is advised. To plan follow-up imaging intervals, the ELAPSS score may help estimatie the 3 - and 5-year risk of aneurysm growth, which is an established surrogate for rupture. The frequency for follow-up imaging can then be planned accordingly $[68,69]$.
In the absence of data from randomized trials specific to $F M D$, management of ceAD among patients with FMD is similar to that of patients without FMD $[3,63]$. In the acute phase and depending on the clinical presentation, intravenous thrombolysis and/or mechanical thrombectomy is applied if the patients meet criteria for treatment [64, 70]. Patients who remain symptomatic, developing TIA or stroke despite optimal medical therapy, and patients with symptoms/signs of cerebrovascular hypoperfusion due to carotid stenosis, can also be treated with mechanical thrombectomy followed or proceeded by carotid artery stenting $[3,71]$. Most patients with ceAD will not require invasive treatment, but antithrombotic treatment - either an anticoagulant or an antiplatelet agent - for at least 3-6 months - is given in order to prevent recurrent ischemic events. Antiplatelet therapy is generally continued lifelong, if not contraindicated $[3,63,70]$. Whether or not lifelong antiplatelet therapy is needed in completed healed ceAD is not known, as there are no supporting data. However, the radiographic morphology (e.g., residual stenosis, dissection-related aneurysm) and the low risk of recurrence, may guide a pragmatic decision made on a case-by-case basis. Pseudoaneurysms resulting from a dissection are at low risk for ischemic events or rupture and rarely require endovascular treatment [72]. As minor traumas are often associated with ceAD, some physical activities or manipulations (roller coaster ride, heavy weight lifting, chiropractic neck manipulation) are best avoided in patients with cerebrovascular FMD $[3,54,63,64]$.

An endoluminal 'carotid web' or 'carotid bulb diaphragm', visualized as a linear defect on CTA or MRA, has been classified as a focal variant of intimal FMD of the carotid bulb by some authors. It has been described predominantly in black/Afro-Caribbean patients and is associated with a high risk of recurrent ischemic stroke, justifying carotid stenting or endarterectomy [73-75].

\section{VISCERAL FMD}

The prevalence of visceral artery (VA) FMD varies between $14 \%-21 \%$ in patients with FMD who underwent systematic imaging studies $[9-13,76]$. This relatively high frequency strengthens the need for a systematic evaluation of all vascular beds, including visceral arteries, regardless of initial FMD involvement. The celiac axis, superior mesenteric and splenic arteries are the most frequently involved (Figure 3). Most patients with VA-FMD are asymptomatic, and VA-FMD is often an incidental finding on imaging studies performed for other reasons. Both liver and intestine are indeed relatively resistant to ischemia (double hepatic blood supply) and collateral circulation through the inferior mesenteric artery (Riolan's arcade), unless at least two of the major arteries are obstructed. Visceral artery FMD can nevertheless present as mesenteric ischemia caused by progressive stenotic lesions of the mesenteric territory, resulting in nausea, postprandial flank or abdominal pain and weight loss; an abdominal bruit can be present at 

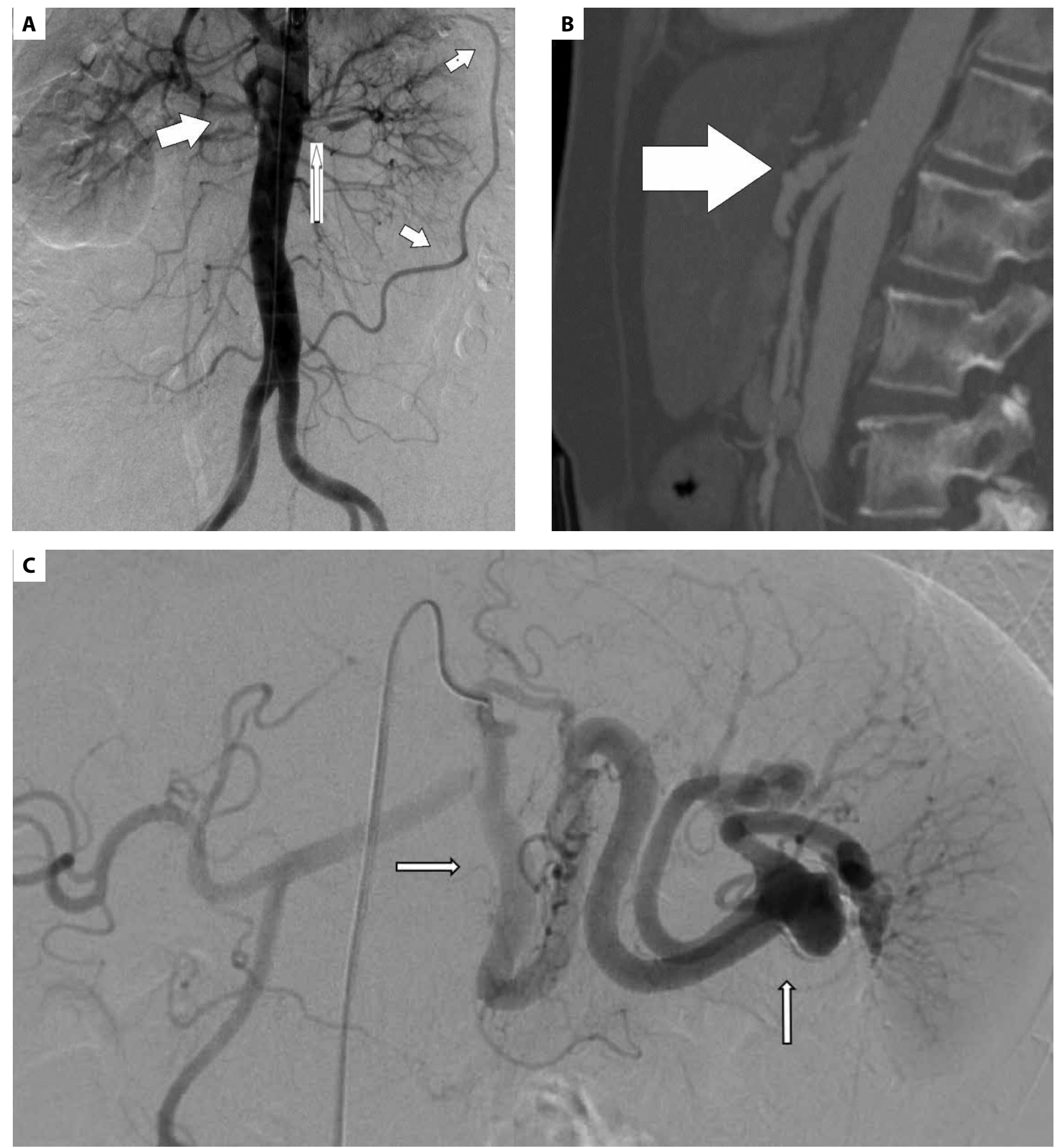

Figure 3. A. Focal stenosis of superior mesenteric artery with prominent arcade of Riolan in a 49-year-old man with focal stenosis of renal artery (long arrow). B. Multifocal-fibromuscular dysplasia (MF-FMD) of the coeliac trunk in a 70-year-old woman with SCAD (courtesy of D. Adlam, Leicester, UK). C. Tortuosity and aneurysm of the splenic artery in a 62-year-old woman with MF-FMD of the right renal and left common iliac arteries

physical examination. Severe forms have been reported, eventually resulting in hemicolectomy, multi-organ failure, and eventually death. Acute ischemia and/or infarction is usually due to arterial dissection or embolism from an aneurysm causing acute abdominal pain and potentially shock $[3,12,13]$. Patients with VA-FMD are more likely to have aneurysms and dissections compared to patients with FMD without visceral involvement [76].

We recently showed that patients with FMD have smaller visceral arterial diameters when compared with patients without FMD. This may represent a new phenotype of FMD. The lower BMI seen in these patients compared to matched controls may be explained by chronic mesenteric ischemia resulting from FMD lesions [77].

\section{Diagnosis}

CTA and MRA are generally used to confirm diagnosis, while catheter-based angiography remains the gold standard. Screening for VA-FMD should not only be performed in symptomatic patients, but also in patients with renal and/ 
or cervicocephalic FMD $[1-3,6,13]$. Conversely, patients with VA-FMD should be screened for renal and/or, to a lesser degree, extracranial involvement, as concomitant renal or cervicocephalic involvement was found in, respectively, $41 / 75$ and 3/75 patients with VA-FMD [52]. The combined involvement was also more frequently present in women than in men (80\% vs $36 \%)$ [78].

\section{Treatment}

Treatment - endovascular or surgical - of VA-FMD depends on symptomatology, type/location and extent of the arterial involvement, the presence of aneurysms or dissections, prior vascular events, comorbid conditions and age of the patient. Smoking is discouraged and arterial hypertension and hyperlipidemia are treated according to the guidelines. Pharmacologic treatment with antiplatelet drugs, in mono or dual therapy, and with anticoagulation is comparable to that proposed for renal FMD [13].

\section{ILIAC AND LOWER EXTREMITY FMD}

Lower extremity FMD has been reported in common iliac, internal iliac, common femoral, deep and superficial femoral and popliteal arteries, but most commonly the external iliac arteries are involved. The lesions are typically multifocal and bilateral $[3,14,52,79]$ (Figure 4A). According to the recent registries, FMD involving the iliac arteries is present in $7 \%-62 \%$ of patients $[9,11,12,14]$. Most patients with lower extremity involvement are asymptomatic and may be diagnosed by femoral bruit noted on physical examination or incidentally on imaging studies. Iliac artery FMD can seldom cause limb symptoms, including claudication, foot or toe ischemia, and atypical leg symptoms, by luminal narrowing, microthrombi with distal embolization and thrombosis due to dissection; aneurysms may also occur, but are seldom complicated by rupture $[3,79,80]$.

\section{Diagnosis}

Duplex ultrasound, CTA, MRA, or catheter-based angiography can be used for the diagnosis; however, DUS will inadequately visualize the iliac arteries. The FMD findings have to be differentiated from atherosclerotic disease based on nature of the lesion and absence of plaque [52].

\section{Treatment}

Angioplasty is the preferred treatment of choice in symptomatic patients and carries a high technical success rate. Surgery is reserved for complicated cases, progressive aneurysm growth following dissection or for treating complications of endovascular treatment. However, most patients are asymptomatic and can be managed conservatively including antiplatelet therapy [14].

\section{UPPER EXTREMITY FMD}

Upper extremity FMD has been reported in 3\% (7/232) and $15.9 \%(10 / 63)$, respectively, of patients who underwent upper extremity imaging in the ARCADIA-POL and US Registries $[10,12]$. It has been documented in the subclavian, axillary, radial, and ulnar arteries, but the brachial artery is most often involved [10, 81] (Figure 4B). Involvement is most commonly of the multifocal type and bilateral. The majority of patients are asymptomatic [81]. If present, symptoms of upper extremity FMD may include Raynaud's phenomenon, paresthesia, hand or arm claudication, and finger or hand ischemia (rest pain, discoloration, ulceration, or gangrene) resulting from thromboembolism or dissection [81]. Brachial FMD can be suspected in asymptomatic
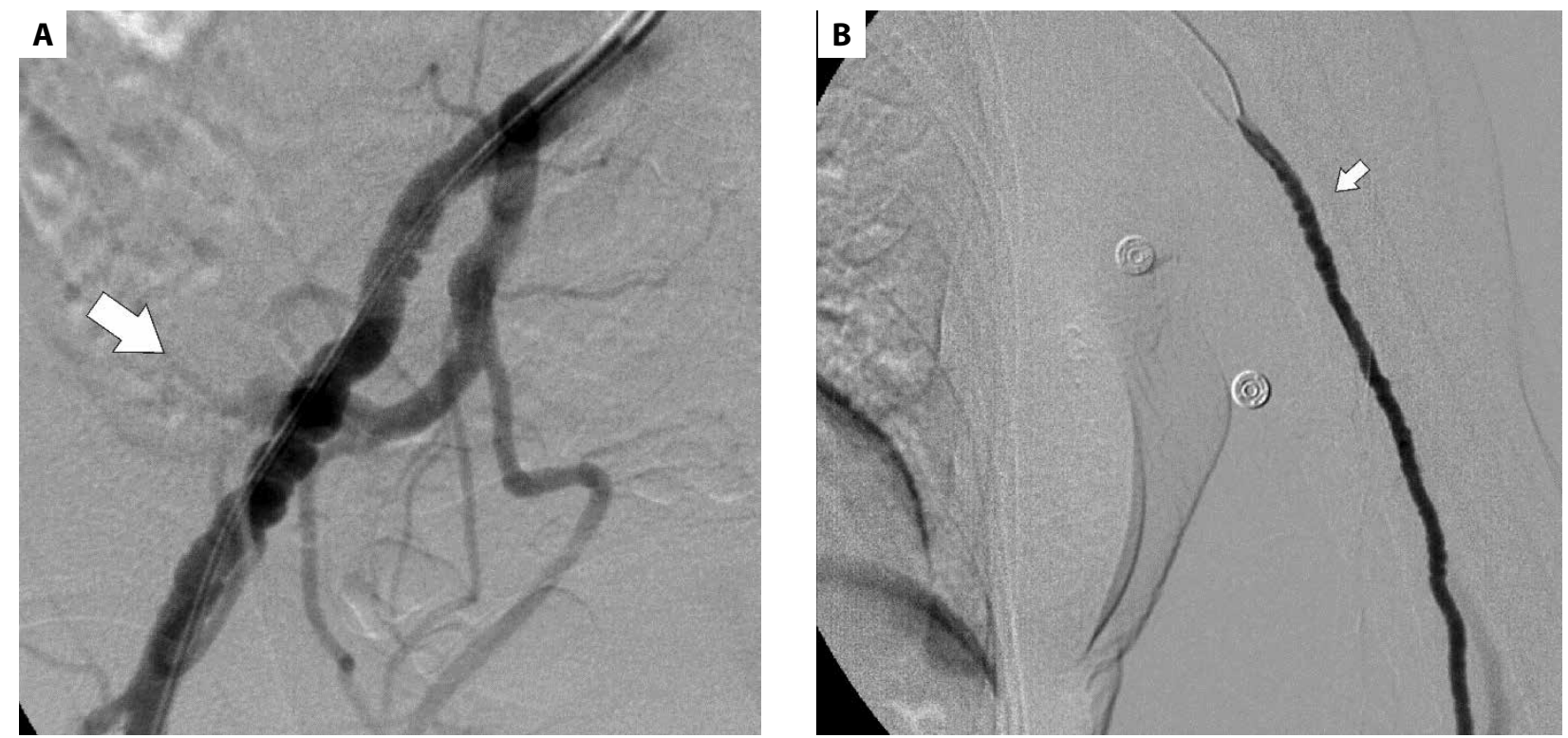

Figure 4. A. Multifocal fibromuscular dysplasia (MF-FMD) of the common iliac artery in a 68-year-old woman with FMD lesions in both renal and common iliac arteries, and tortuosity of both vertebral and common carotid arteries. B. MF-FMD of the right brachial artery in a 67-year-old woman 
subjects, if a brachial bruit and/or discrepant arm blood pressures are identified on physical examination [81].

\section{Diagnosis}

Diagnosis can be made by DUS, as atherosclerosis is uncommon in upper extremity arteries, except in patients with severe chronic kidney disease (Mönckeberg's sclerosis). However, many other diseases can cause a Raynaud phenomenon and upper extremity ischemia. Therefore, whenever the underlying cause is uncertain, and especially if digital ischemia is unilateral, imaging with arteriography is recommended to detect potentially treatable (endovascular or surgical) diseased arteries. Usually, CTA or MRA is performed as initial diagnostic tool, while catheter-based angiography is reserved to rare patients who need vascular intervention [3].

\section{Treatment}

Depending on the presentation, treatment can be conservative, endovascular with angioplasty, or surgical with thrombolysis, excision/resection of the diseased artery segment with primary anastomosis or grafting with reversed saphenous vein [81-83].

\section{CORONARY FMD AND SCAD}

Spontaneous coronary artery dissection (SCAD) is an uncommon cause of acute coronary syndromes, and occurs predominantly in young to middle-aged women [84-87]. Saw et al. [87] published the first case series of SCAD with concomitant FMD. Since then, several other extra-coronary arterial lesions including aneurysms, dissections, focal stenosis, and aortic root dilation have been described in patients with SCAD [88]. While SCAD is rare in patients with FMD, being present in only $2.7 \%$ of patients in the US FMD Registry, the prevalence of FMD in SCAD survivors ranges between $41 \%$ and $86 \%$ of SCAD-survivors, depending on modality and completeness of imaging $[6,84]$. The most common affected vascular beds are the cervical, renal, and ilio-femoral arteries [84]. Extracoronary FMD in SCAD patients is mostly of the multifocal phenotype and appears to be benign and non-progressive in the short to medium term, with low reported rates of non-coronary major adverse cardiovascular events in SCAD-survivors $[84,88,89]$. Following discovery of the association between SCAD and extra-coronary MF-FMD, and despite the extreme rarity of typical coronary string of beads, the concept of coronary FMD has been proposed [87, 88, 90-92]. The latter should be considered in presence of marked coronary tortuosity - usually defined as $\geq 3$ bends (defined as a $\geq 45^{\circ}$ change in vessel direction) - however, the intravessel or multivessel symmetry sign, corkscrew appearance, dissection, aneurysm, distal tapering or long, smooth narrowing of the coronary arteries have all been described [92]. To ascribe these lesions to FMD, the presence of at least one focal or multifocal arterial lesion in another vascular bed is required.
Coronary artery tortuosity is also highly prevalent in the SCAD population and is associated with recurrent SCAD, which occurs most often within segments of tortuosity [93]. Nevertheless, arterial tortuosity may have multiple causes, may be found in apparently healthy subjects and is also associated with increasing age, female gender and cardiovascular risk factors [94].

SCAD and FMD share common genetic risk variants including the PHACTR1 locus [95]. Notably however, the effect size may be different between patients presenting primarily with SCAD or with FMD $[84,95,96]$. Common genetic variants associated with SCAD are also associated with SCAD risk among patients with FMD [86]. Overall, these data may suggest that SCAD and FMD are not a single disease but rather overlapping disorders [19]. Further research is in progress [97].

\section{Treatment}

Overall, based on expert opinion and observational data, a conservative approach is preferred in patients with SCAD when possible $[84,85,98]$. A treatment algorithm is proposed in the recent ESC guidelines [98].

\section{CONCLUSIONS}

FMD is an idiopathic, segmental, nonatherosclerotic, noninflammatory disease of the musculature of small to medium-sized arteries. It cannot be considered a rare disease of young women anymore. Indeed, though predominant in female sex, it may be diagnosed both in men and women and at any age. While renal and cervical arteries are the most frequently affected, FMD may be found in all arterial beds and multivessel involvement is common. FMD primarily manifests as multifocal ('string-of-beads') or focal lesions, but arterial aneurysms, dissections and tortuosity are frequent manifestations of the disease. The clinical course of FMD is highly variable, from incidental findings to life-threatening lesions. Confirmation of the diagnosis requires CT-, MR- or catheter-based angiography. Regardless of the initial site of vascular bed involvement, imaging of all vessels from brain to pelvis should be performed at least once. Treatment depends on the clinical presentation and can be conservative as well as invasive. Ongoing research is promising for our patients.

\section{Article information}

Conflict of interest: None declared.

Open access: This article is available in open access under Creative Common Attribution-Non-Commercial-No Derivatives 4.0 International (CC BY-NC-ND 4.0) license, allowing to download articles and share them with others as long as they credit the authors and the publisher, but without permission to change them in any way or use them commercially. For commercial use, please contact the journal office at kardiologiapolska@ptkardio.pl.

How to cite: Van der Niepen P, Robberechts T, Devos H, et al. Fibromuscular dysplasia: its various phenotypes in everyday practice in 2021. Kardiol Pol. 2021;79(7-8): 733-744, doi: 10.33963/KP.a2021.0040. 


\section{REFERENCES}

1. Persu A, Giavarini A, Touzé E, et al. ESH Working Group Hypertension and the Kidney. European consensus on the diagnosis and management of fibromuscular dysplasia. J Hypertens. 2014; 32(7): 1367-1378, doi: 10.1097/HJH.0000000000000213, indexed in Pubmed: 24842696.

2. Persu A, Van der Niepen P, Touzé E, et al. Working Group "Hypertension and the Kidney" of the European Society of Hypertension and the European Fibromuscular Dysplasia Initiative. Revisiting fibromuscular dysplasia: rationale of the European Fibromuscular Dysplasia Initiative. Hypertension. 2016; 68(4): 832-839, doi: 10.1161/HYPERTENSIONAHA.116.07543, indexed in Pubmed: 27504007.

3. Gornik HL, Persu A, Adlam D, et al. Working Group 'Hypertension and the Kidney' of the European Society of Hypertension (ESH) and the Society for Vascular Medicine (SVM). First international consensus on the diagnosis and management of fibromuscular dysplasia. JHypertens. 2019;37(2):229-252, doi: 10.1097/HJH.0000000000002019, indexed in Pubmed: 30640867.

4. Olin JW, Gornik HL, Bacharach JM, et al. American Heart Association Council on Peripheral Vascular Disease, American Heart Association Council on Clinical Cardiology, American Heart Association Council on Cardiopulmonary, Critical Care, Perioperative and Resuscitation, American Heart Association Council on Cardiovascular Disease in the Young, American Heart Association Council on Cardiovascular Radiology and Intervention, American Heart Association Council on Epidemiology and Prevention, American Heart Association Council on Functional Genomics and Translational Biology, American Heart Association Council for High Blood Pressure Research, American Heart Association Council on the Kidney in Cardiovascular Disease, American Heart Association Stroke Council. Fibromuscular dysplasia: state of the science and critical unanswered questions: a scientific statement from the American Heart Association. Circulation. 2014; 129(9): 1048-1078, doi: 10.1161/01. cir.0000442577.96802.8c, indexed in Pubmed: 24548843.

5. Savard S, Steichen O, Azarine A, et al. Association between 2 angiographic subtypes of renal artery fibromuscular dysplasia and clinical characteristics. Circulation. 2012; 126(25): 3062-3069, doi: 10.1161/CIRCULATIONAHA.112.117499, indexed in Pubmed: 23155180.

6. Kadian-Dodov D, Gornik HL, Gu X, et al. Dissection and aneurysm in patients with fibromuscular dysplasia: findings from the U.S. Registry for FMD. J Am Coll Cardiol. 2016; 68(2): 176-185, doi: 10.1016/j. jacc.2016.04.044, indexed in Pubmed: 27386771.

7. Lather HD, Gornik HL, Olin JW, et al. Prevalence of intracranial aneurysm in women with fibromuscular dysplasia: a report from the US Registry for Fibromuscular Dysplasia. JAMA Neurol. 2017; 74(9): 1081-1087, doi: 10.1001/jamaneurol.2017.1333, indexed in Pubmed: 28715558.

8. Sethi SS, Lau JF, Godbold J, et al. The S curve: a novel morphological finding in the internal carotid artery in patients with fibromuscular dysplasia. Vasc Med. 2014; 19(5):356-362, doi: 10.1177/1358863X14547122, indexed in Pubmed: 25135311.

9. Pappaccogli M, Di Monaco S, Warchoł-Celińska E, et al. European/International FMD Registry and Initiative (FEIRI), and the Working Group 'Hypertension and the Kidney' of the European Society of Hypertension (ESH). The European/International Fibromuscular Dysplasia Registry and Initiative (FEIRI) - clinical phenotypes and their predictors based on a cohort of 1000 patients. Cardiovasc Res. 2021; 117(3): 950-959, doi: 10.1093/cvr/cvaa102, indexed in Pubmed: 32282921.

10. Olin JW, Froehlich J, Gu X, et al. The United States Registry for Fibromuscular Dysplasia: results in the first 447 patients. Circulation. 2012; 125(25): 3182-3190, doi: 10.1161/CIRCULATIONAHA.112.091223, indexed in Pubmed: 22615343.

11. Plouin PF, Baguet JP, Thony F, et al. ARCADIA Investigators. High prevalence of multiple arterial bed lesions in patients with fibromuscular dysplasia: the ARCADIA registry (Assessment of Renal and Cervical Artery Dysplasia). Hypertension. 2017; 70(3): 652-658, doi: 10.1161/HYPERTENSIONAHA.117.09539, indexed in Pubmed: 28716989.

12. Warchol-Celinska E, Hanus K, FlorczakE, et al. [PP.09.05] The Polish Registry for Fibromuscular Dysplasia (ARCADIA-POL study) — distribution of vascular bed involvement and complications in patients with fibromuscular dysplasia. J Hypertens. 2017; 35(Suppl 2): e151-e152, doi: 10.1097/01. hjh.0000523406.36625.62.
13. Van der Niepen $P$, van TussenbroekF, Devos $H$, et al. Visceral fibromuscular dysplasia: from asymptomatic disorder to emergency. Eur J Clin Invest. 2018; 48(11): e13023, doi: 10.1111/eci.13023, indexed in Pubmed: 30156710.

14. Brinza E, Grabinski V, Durga S, et al. Lower extremity fibromuscular dysplasia: clinical manifestations, diagnostic testing, and approach to management. Angiology. 2017;68(8): 722-727, doi: 10.1177/0003319716682121, indexed in Pubmed: 28006960.

15. De Groote $M$, Van der Niepen $P$, Hemelsoet $D$, et al. Fibromuscular dysplasia - results of a multicentre study in Flanders. Vasa. 2017;46(3):211-218, doi: 10.1024/0301-1526/a000613, indexed in Pubmed: 28157058.

16. Warchol-Celinska E, Prejbisz A, Dobrowolski P, et al. Systematic and multidisciplinary evaluation of fibromuscular dysplasia patients reveals high prevalence of previously undetected fibromuscular dysplasia lesions and affects clinical decisions: the ARCADIA-POL study. Hypertension. 2020; 75(4): 1102-1109, doi: 10.1161/HYPERTENSIONAHA.119.13239, indexed in Pubmed: 32148126.

17. Berra E, Dominiczak AF, Touyz RM, et al. Management of a pregnant woman with fibromuscular dysplasia. Hypertension. 2018; 71(4):540-547, doi: 10.1161/HYPERTENSIONAHA.118.10819, indexed in Pubmed: 29483231.

18. Pappaccogli M, Prejbisz A, Ciurică S, et al. European/International Fibromuscular Dysplasia Registry and Initiative (FEIRI) and the Working Group "Hypertension and the Kidney" of the ESH. Pregnancy-Related complications in patients with fibromuscular dysplasia: a report from the European/International Fibromuscular Dysplasia Registry. Hypertension. 2020; 76(2): 545-553, doi: 10.1161/HYPERTENSIONAHA.120.15349, indexed in Pubmed: 32639884

19. Persu A, Dobrowolski P, Gornik HL, et al. Current progress in clinical, molecular, and genetic aspects of adult fibromuscular dysplasia. Cardiovasc Res. 2021 [Epub ahead of print], doi: 10.1093/cvr/cvab086, indexed in Pubmed: 33739371.

20. Kim ESH, Olin JW, Froehlich JB, et al. Clinical manifestations of fibromuscular dysplasia vary by patient sex: a report of the United States registry for fibromuscular dysplasia. J Am Coll Cardiol. 2013; 62(21): 2026-2028, doi: 10.1016/j.jacc.2013.07.038, indexed in Pubmed: 23954333.

21. Kiando SR, Tucker NR, Castro-Vega $\sqcup$, et al. PHACTR1 is a genetic susceptibility locus for fibromuscular dysplasia supporting its complex genetic pattern of inheritance. PLoS Genet. 2016; 12(10): e1006367, doi: 10.1371/journal.pgen.1006367, indexed in Pubmed: 27792790.

22. Savard S, Azarine A, Jeunemaitre $X$, et al. Association of smoking with phenotype at diagnosis and vascular interventions in patients with renal artery fibromuscular dysplasia. Hypertension. 2013; 61(6): 1227-1232, doi: 10.1161/HYPERTENSIONAHA.111.00838, indexed in Pubmed: 23608656.

23. O'Connor S, Gornik HL, Froehlich JB, et al. Smoking and adverse outcomes in fibromuscular dysplasia: U.S. Registry Report. J Am Coll Cardiol. 2016; 67(14): 1750-1751, doi: 10.1016/j.jacc.2016.01.058, indexed in Pubmed: 27056782.

24. McKenzie GA, Oderich GS, Kawashima A, et al. Renal artery fibromuscular dysplasia in 2,640 renal donor subjects: a CT angiography analysis. J Vasc Interv Radiol. 2013; 24(10): 1477-1480, doi: 10.1016/j.jvir.2013.06.006, indexed in Pubmed: 23911200.

25. Hendricks NJ, Matsumoto AH, Angle JF, et al. Is fibromuscular dysplasia underdiagnosed? A comparison of the prevalence of FMD seen in CORAL trial participants versus a single institution population of renal donor candidates. Vasc Med. 2014; 19(5):363-367, doi: 10.1177/1358863X14544715, indexed in Pubmed: 25082538.

26. Shivapour DM, Erwin P, Kim ESh. Epidemiology of fibromuscular dysplasia: a review of the literature. Vasc Med. 2016; 21(4): 376-381, doi: 10.1177/1358863X16637913, indexed in Pubmed: 27067138.

27. Faucon AL, Bobrie G, Azarine A, et al. Renal outcome and new-onset renal and extrarenal dissections in patients with nontrauma renal artery dissection associated with renal infarction. Hypertension. 2021;78(1):51-61, doi: 10.1161/HYPERTENSIONAHA.120.16540, indexed in Pubmed: 33966454.

28. Faucon AL, Bobrie G, Jannot AS, et al. Cause of renal infarction: a retrospective analysis of 186 consecutive cases. J Hypertens. 2018; 36(3): 634-640, doi: 10.1097/HJH.0000000000001588, indexed in Pubmed: 29045340.

29. Lengelé JP, Christophe JL, Persu A. Renal infarction management: towards an etiological approach? J Hypertens. 2018; 36(3): 490-492, doi: 10.1097/HJH.0000000000001629, indexed in Pubmed: 29384986. 
30. van Twist DJL, de Heer PWM, Houben AJ, et al. Differences in renal hemodynamics and renin secretion between patients with unifocal and multifocal fibromuscular dysplasia. J Hypertens. 2018; 36(8): 1729-1735, doi: 10.1097/HJH.0000000000001755, indexed in Pubmed: 29889158.

31. De Bruyne B, Manoharan G, Pijls NHJ, et al. Assessment of renal artery stenosis severity by pressure gradient measurements. J Am Coll Cardiol. 2006; 48(9): 1851-1855, doi: 10.1016/j.jacc.2006.05.074, indexed in Pubmed: 17084261.

32. Raju MG, Bajzer CT, Clair DG, et al. Renal artery stent fracture in patients with fibromuscular dysplasia: a cautionary tale. Circ Cardiovasc Interv. 2013; 6(3): e30-e31, doi: 10.1161/CIRCINTERVENTIONS.113.000193, indexed in Pubmed: 23780296.

33. Wang LC, Scott DJ, Clemens MS, et al. Mechanism of stent failure in a patient with fibromuscular dysplasia following renal artery stenting. Ann Vasc Surg. 2015;29(1): 123.e19-123.e21, doi: 10.1016/j.avsg.2014.08.002, indexed in Pubmed: 25192822.

34. Lacombe M, Ricco JB. Surgical revascularization of renal artery after complicated or failed percutaneous transluminal renal angioplasty. J Vasc Surg. 2006; 44(3): 537-544, doi: 10.1016/j.jvs.2006.05.036, indexed in Pubmed: 16950431.

35. Brownstein AJ, Erben Y, Rajaee $S$, et al. Natural history and management of renal artery aneurysms in a single tertiary referral center. J Vasc Surg. 2018; 68(1): 137-144, doi: 10.1016/j.jvs.2017.10.086, indexed in Pubmed: 29398313.

36. Augustin $\mathrm{G}$, Kulis $\mathrm{T}$, Kello $\mathrm{N}$, et al. Ruptured renal artery aneurysm in pregnancy and puerperium: literature review of 53 cases. Arch Gynecol Obstet. 2019;299(4): 923-931, doi: 10.1007/s00404-019-05087-y, indexed in Pubmed: 30739174.

37. HenkePK, Cardneau JD, Welling TH, et al. Renal artery aneurysms: a 35-year clinical experience with 252 aneurysms in 168 patients. Ann Surg. 2001; 234(4): 454-463, doi: 10.1097/00000658-200110000-00005, indexed in Pubmed: 11573039.

38. Kawase T, Inoue Y, Matsuo J, et al. Results of surgical repair of hilar renal artery aneurysm to preserve renal blood flow. Ann Vasc Dis. 2020; 13(3): 281-285, doi: 10.3400/avd.oa.20-00020, indexed in Pubmed: 33384731.

39. Jayet J, Davaine JM, Tresson $P$, et al. Direct distal renal artery aneurysm repair. Eur J Vasc Endovasc Surg. 2020; 60(2): 211-218, doi: 10.1016/j. ejvs.2020.04.016, indexed in Pubmed: 32402807.

40. Finch LM, Spiers HVM, Chinnadurai R, et al. Endovascular coiling in the treatment of patients with renal artery aneurysms. J Vasc Surg Cases Innov Tech. 2021;7(2):307-310, doi: 10.1016/j.jvscit.2021.03.006, indexed in Pubmed: 34027245.

41. Trinquart L, Mounier-Vehier C, Sapoval M, et al. Efficacy of revascularization for renal artery stenosis caused by fibromuscular dysplasia: a systematic review and meta-analysis. Hypertension. 2010; 56(3): 525-532, doi: 10.1161/HYPERTENSIONAHA.110.152918, indexed in Pubmed: 20625080.

42. Rosławiecka A, Kabłak-Ziembicka A, Badacz R, et al. Long-term outcomes and determinants of stenosis recurrence after renal artery angioplasty in hypertensive patients with renovascular disease. Postepy Kardiol Interwencyjnej. 2020; 16(1):65-75, doi: 10.5114/aic.2019.91309, indexed in Pubmed: 32368238.

43. Gross CM, Krämer J, Weingärtner $\mathrm{O}$, et al. Determination of renal arterial stenosis severity: comparison of pressure gradient and vessel diameter. Radiology. 2001; 220(3): 751-756, doi: 10.1148/radiol.2203001444, indexed in Pubmed: 11526278.

44. Mahmud E, Brocato M, Palakodeti V, et al. Fibromuscular dysplasia of renal arteries: percutaneous revascularization based on hemodynamic assessment with a pressure measurement guidewire. Catheter Cardiovasc Interv. 2006; 67(3): 434-437, doi: 10.1002/ccd.20621, indexed in Pubmed: 16475187.

45. Onoue $Y$, Tsujita $K$, Hokimoto $S$, et al. In vivo intravascular ultrasound imaging of fibromuscular dysplastic region and intravascular pressure gradient-guided percutaneous transluminal renal angioplasty. J Cardiol Cases. 2011; 4(3): e163-e167, doi: 10.1016/j.jccase.2011.08.006, indexed in Pubmed: 30532886.

46. Gavalas MV, Gasparis AP, Tassiopoulos AK, et al. Long-term follow-up for percutaneous transluminal angioplasty in renal artery fibromuscular dysplasia. Int Angiol. 2015;34(6):529-537, indexed in Pubmed: 24824840.

47. Oribe $S$, Toyohara $T$, Mishima $E$, et al. Fibromuscular dysplasia with recurrence after "long-term" following percutaneous transcatheter renal angioplasty: two case reports with a review of 26 patients. BMC
Nephrol. 2021; 22(1): 187, doi: 10.1186/s12882-021-02342-w, indexed in Pubmed: 34016044.

48. Williams B, Mancia G, Spiering W, et al. 2018 ESC/ESH Guidelines for the management of arterial hypertension. The task force for the management of arterial hypertension of the European Society of Cardiology and the European Society of Hypertension: the task force for the management of arterial hypertension of the European Society of Cardiology and the European Society of Hypertension. J Hypertens. 2018; 36(10): 1953-2041, doi: 10.1097/HJH.0000000000001940, indexed in Pubmed: 30234752.

49. Whelton PK, Carey RM, Aronow WS, et al. 2017 ACC/AH/AAPA/ /ABC/ACPM/AGS/APHA/ASH/ASPC/NMA/PCNA guideline for the prevention, detection, evaluation, and management of high blood pressure in adults: a report of the American College of Cardiology/American Heart Association Task Force on Clinical Practice Guidelines. J Am Coll Cardiol. 2018; 71(19): e127-e248, doi: 10.1016/j.jacc.2017.11.006, indexed in Pubmed: 29146535.

50. Mach F, Baigent C, Catapano AL, et al. ESC Scientific Document Group. 2019 ESC/EAS Guidelines for the management of dyslipidaemias: lipid modification to reduce cardiovascular risk. Eur Heart J. 2020; 41(1): 111-188, doi: 10.1093/eurheartj/ehz455, indexed in Pubmed: 31504418.

51. DobrowolskiP, Januszewicz M, Witowicz H, etal.Prevalence of smoking and clinical characteristics in fibromuscular dysplasia. The ARCADIA-POL study. Blood Press. 2019; 28(1): 49-56, doi: 10.1080/08037051.2018.1514252, indexed in Pubmed: 30560699.

52. Bolen MA, Brinza E, Renapurkar RD, et al. Screening CT angiography of the aorta, visceral branch vessels, and pelvic arteries in fibromuscular dysplasia. JACC Cardiovasc Imaging. 2017; 10(5):554-561, doi: 10.1016/j. jcmg.2016.04.010, indexed in Pubmed: 27665159.

53. Touzé $E$, Southerland AM, Boulanger $M$, et al. Fibromuscular dysplasia and its neurologic manifestations: a systematic review. JAMA Neurol. 2019; 76(2): 217-226, doi: 10.1001/jamaneurol.2018.2848, indexed in Pubmed: 30285053.

54. Harriott $A M$, Zimmerman $E$, Singhal $A B$, et al. Cerebrovascular fibromuscular dysplasia: the MGH cohort and literature review. Neurol Clin Pract. 2017; 7(3): 225-236, doi: 10.1212/CPJ.0000000000000339, indexed in Pubmed: 28680766.

55. Wells BJ, Modi RD, Gu X, et al. Clinical associations of headaches among patients with fibromuscular dysplasia: a report from the US Registry for Fibromuscular Dysplasia. Vasc Med. 2020; 25(4): 348-350, doi: 10.1177/1358863X20923740, indexed in Pubmed: 32490735.

56. Sismanis A. Pulsatile tinnitus: contemporary assessment and management. Curr Opin Otolaryngol Head Neck Surg. 2011; 19(5): 348-357, doi: 10.1097/MO0.0b013e3283493fd8, indexed in Pubmed: 22552697.

57. Lather HD, Gornik HL, Olin JW, et al. Prevalence of intracranial aneurysm in women with fibromuscular dysplasia: a report from the US Registry for Fibromuscular Dysplasia. JAMA Neurol. 2017; 74(9): 1081-1087, doi: 10.1001/jamaneurol.2017.1333, indexed in Pubmed: 28715558.

58. Hackenberg KAM, Etminan N. Neurovascular disease, diagnosis, and therapy: Brain aneurysms. Handb Clin Neurol. 2021; 176: 121-134, doi: 10.1016/B978-0-444-64034-5.00001-8, indexed in Pubmed: 33272392.

59. Talarowska P, Dobrowolski P, Klisiewicz A, et al. High incidence and clinical characteristics of fibromuscular dysplasia in patients with spontaneous cervical artery dissection: the ARCADIA-POL study. Vasc Med. 2019; 24(2): 112-119, doi: 10.1177/1358863X18811596, indexed in Pubmed: 30739593.

60. Arnaud C, Boulanger M, Lorthioir A, et al. ARCADIA Co-investigators †. Male sex is associated with cervical artery dissection in patients with fibromuscular dysplasia. J Am Heart Assoc. 2021; 10(11): e018311, doi: 10.1161/JAHA.120.018311, indexed in Pubmed: 33998257.

61. de Bray JM, Marc G, Pautot V, et al. Fibromuscular dysplasia may herald symptomatic recurrence of cervical artery dissection. Cerebrovasc Dis. 2007; 23(5-6): 448-452, doi: 10.1159/000101470, indexed in Pubmed: 17406116.

62. Béjot $Y$, Aboa-Eboulé $C$, Debette $S$, et al. CADISP Group. Characteristics and outcomes of patients with multiple cervical artery dissection. Stroke. 2014; 45(1): 37-41, doi: 10.1161/STROKEAHA.113.001654, indexed in Pubmed: 24326451

63. Bonacina S, Locatelli M, Mazzoleni V, et al. Spontaneous cervical artery dissection and fibromuscular dysplasia: Epidemiologic and biologic evidence of a mutual relationship. Trends Cardiovasc Med. 2021 [Epub ahead of print], doi: 10.1016/j.tcm.2021.01.006, indexed in Pubmed: 33524506. 
64. Debette S. Pathophysiology and risk factors of cervical artery dissection: what have we learnt from large hospital-based cohorts? Curr Opin Neurol. 2014; 27(1): 20-28, doi: 10.1097/WCO.0000000000000056, indexed in Pubmed: 24300790.

65. Bonacina S, Grassi M, Zedde M, et al. IPSYS CeAD Research Group*.Clinical features of patients with cervical artery dissection and fibromuscular dysplasia. Stroke. 2021; 52(3):821-829, doi: 10.1161/STROKEAHA.120.031579, indexed in Pubmed: 33504192.

66. Kadian-Dodov D, Goldfinger JZ, Gustavson S, et al. Natural history of cervical artery fibromuscular dysplasia and associated neurovascular events. Cerebrovasc Dis. 2018; 46(1-2): 33-39, doi: 10.1159/000491437, indexed in Pubmed: 30064124.

67. O'Connor SC, Poria N, Gornik HL. Fibromuscular dysplasia: an update for the headache clinician. Headache. 2015; 55(5): 748-755, doi: 10.1111/head.12560, indexed in Pubmed: 25882138.

68. Abdalkader M, Nguyen TN, Norbash AM, et al. State of the art: venous causes of pulsatile tinnitus and diagnostic considerations guiding endovascular therapy. Radiology. 2021 [Epub ahead of print]: 202584, doi: 10.1148/radiol.2021202584, indexed in Pubmed: 34032509.

69. Backes D, Rinkel GJE, Greving JP, et al. ELAPSS score for prediction of risk of growth of unruptured intracranial aneurysms. Neurology. 2017; 88(17): 1600-1606, doi: 10.1212/WNL.0000000000003865, indexed in Pubmed: 28363976.

70. Markus HS, LeviC, King A, et al.Cervical Artery Dissection in Stroke Study (CADISS) Investigators. Antiplatelet therapy vs anticoagulation therapy in cervical artery dissection: the Cervical Artery Dissection in Stroke Study (CADISS) randomized clinical trial final results. JAMA Neurol. 2019; 76(6):657-664, doi: 10.1001/jamaneurol.2019.0072, indexed in Pubmed: 30801621.

71. Narula N, Kadian-Dodov D, Olin JW. Fibromuscular dysplasia: contemporary concepts and future directions. Prog Cardiovasc Dis. 2018; 60(6): 580-585, doi: 10.1016/j.pcad.2018.03.001, indexed in Pubmed: 29534984.

72. Larsson SC, King A, Madigan J, etal. Prognosis of carotid dissecting aneurysms: Results from CADISS and a systematic review. Neurology. 2017; 88(7): 646652, doi: 10.1212/WNL.0000000000003617, indexed in Pubmed: 28087823.

73. Zhang AJ, Dhruv $P, C$ hoi $P$, et al. A systematic literature review of patients with carotid web and acute ischemic stroke. Stroke. 2018; 49(12): 2872 2876, doi: 10.1161/STROKEAHA.118.021907, indexed in Pubmed:30571430.

74. Kim SJ, Nogueira RG, Haussen DC. Current understanding and gaps in research of carotid webs in ischemic strokes: a review. JAMA Neurol. 2019; 76(3): 355-361, doi: 10.1001/jamaneurol.2018.3366, indexed in Pubmed: 30398546.

75. GuglielmiV, Compagne KCJ,Sarrami AH, et al. MRCLEAN trial and MRCLEAN Registry Investigators. Assessment of recurrent stroke risk in patients with a carotid web. JAMA Neurol. 2021 [Epub ahead of print]: e211101, doi: 10.1001/jamaneurol.2021.1101, indexed in Pubmed: 33970205.

76. Moore EK, Gu X, Olin JW. Registry findings of fibromuscular dysplasia of the mesenteric arteries. Vasc Med. 2014; 19: 224-225.

77. Warchoł-Celińska E, Pieluszczak K, Pappaccogli M, et al. Dissecting visceral fibromuscular dysplasia reveals a new vascular phenotype of the disease: a report from the ARCADIA-POL study. J Hypertens. 2020; 38(4): 737-744, doi: 10.1097/HJH.0000000000002327, indexed in Pubmed: 31913220.

78. Mitchell A, Caty V, Bendavid Y. Massive mesenteric panniculitis due to fibromuscular dysplasia of the inferior mesenteric artery: a case report. BMC Gastroenterol.2015; 15:71, doi: 10.1186/s12876-015-0303-5, indexed in Pubmed: 26100669.

79. Okazaki J, Guntani A, Homma K, et al. Fibromuscular dysplasia of the lower extremities. Ann Vasc Dis. 2011; 4(2): 143-149, doi: 10.3400/avd. cr.10.01027, indexed in Pubmed: 23555446.

80. Ketha SS, Bjarnason $\mathrm{H}$, Oderich GS, et al. Clinical features and endovascular management of iliac artery fibromuscular dysplasia. J Vasc Interv Radiol. 2014; 25(6): 949-953, doi: 10.1016/j.jvir.2014.03.002, indexed in Pubmed: 24768236.

81. Nguyen N, Sharma A, West JK, et al. Presentation, clinical features, and results of intervention in upper extremity fibromuscular dysplasia. J Vasc Surg. 2017; 66(2): 554-563, doi: 10.1016/j.jvs.2017.02.049, indexed in Pubmed: 28735951.

82. Shin JS, Han EM, Min BZ, et al. Fibromuscular dysplasia of bilateral brachial arteries treated with surgery and consecutive thrombolytic therapy. Ann Vasc Surg. 2007; 21(1): 93-96, doi: 10.1016/j.avsg.2006.03.001, indexed in Pubmed: 17349345.
83. Antonescu I, Knowles M, Wirtz E, et al. An unusual case of bilateral upper extremity ischemia caused by forearm vessel fibromuscular dysplasia. Ann Vasc Surg. 2019; 56:353.e7-353.e11, doi: 10.1016/j.avsg.2018.08.110, indexed in Pubmed: 30500650.

84. Adlam D, Alfonso F, Maas A, et al. Writing Committee. European Society of Cardiology, acute cardiovascular care association, SCAD study group: a position paper on spontaneous coronary artery dissection. Eur Heart J. 2018; 39(36): 3353-3368, doi: 10.1093/eurheartj/ehy080, indexed in Pubmed: 29481627.

85. Saw J, Mancini GB, Humphries KH. Contemporary review on spontaneous coronary artery dissection. J Am Coll Cardiol. 2016; 68(3): 297-312, doi: 10.1016/j.jacc.2016.05.034, indexed in Pubmed: 27417009.

86. Saw J, Yang ML, Trinder M, et al. Chromosome 1q21.2 and additional loci influence risk of spontaneous coronary artery dissection and myocardial infarction. Nat Commun. 2020; 11(1): 4432, doi: 10.1038/s41467-02017558-x, indexed in Pubmed: 32887874.

87. Saw J, Poulter R, Fung $A$, et al. Spontaneous coronary artery dissection in patients with fibromuscular dysplasia: a case series. Circ Cardiovasc Interv. 2012;5(1): 134-137, doi: 10.1161/CIRCINTERVENTIONS.111.966630, indexed in Pubmed: 22338003.

88. Prasad M, Tweet MS, Hayes SN, et al. Prevalence of extracoronary vascular abnormalities and fibromuscular dysplasia in patients with spontaneous coronary artery dissection. Am J Cardiol. 2015; 115(12): 1672-1677, doi: 10.1016/j.amjcard.2015.03.011, indexed in Pubmed: 25929580.

89. Hayes SN, Kim ESH, Saw J, et al. American Heart Association Council on Peripheral Vascular Disease; Council on Clinical Cardiology; Council on Cardiovascular and Stroke Nursing; Council on Genomic and Precision Medicine; and Stroke Council. Spontaneous coronary artery dissection: current state of the science: a scientific statement from the American Heart Association. Circulation. 2018; 137(19): e523-e557, doi: 10.1161/CIR.0000000000000564, indexed in Pubmed: 29472380.

90. Schweis F, Rostomian AH, Phan D, et al. Multivessel spontaneous coronary artery dissection with coronary artery fibromuscular dysplasia. CJC Open. 2021; 3(5): 687-689, doi: 10.1016/j.cjco.2020.12.021, indexed in Pubmed: 34036260

91. Saw J, Bezerra $\mathrm{H}$, Gornik HL, et al. Angiographic and intracoronary manifestations of coronary fibromuscular dysplasia. Circulation. 2016; 133(16): 1548-1559, doi: 10.1161/CIRCULATIONAHA.115.020282, indexed in Pubmed: 26957531.

92. Michelis KC, Olin JW, Kadian-Dodov D, et al. Coronary artery manifestations of fibromuscular dysplasia. J Am Coll Cardiol. 2014; 64(10): 1033-1046, doi: 10.1016/j.jacc.2014.07.014, indexed in Pubmed: 25190240.

93. Eleid MF, Guddeti RR, Tweet MS, et al. Coronary artery tortuosity in spontaneous coronary artery dissection: angiographic characteristics and clinical implications. Circ Cardiovasc Interv. 2014; 7(5): 656-662, doi: 10.1161/CIRCINTERVENTIONS.114.001676, indexed in Pubmed: 25138034.

94. Ciurică S, Lopez-Sublet M, Loeys BL, et al. Arterial tortuosity. Hypertension. 2019; 73(5): 951-960, doi: 10.1161/HYPERTENSIONAHA.118.11647, indexed in Pubmed: 30852920

95. Adlam D, Olson TM, Combaret N, et al. DISCO Consortium, CARDloGRAMPlusC4D Study Group. Association of the PHACTR1/EDN1 genetic locus with spontaneous coronary artery dissection. J Am Coll Cardiol. 2019; 73(1): 58-66, doi: 10.1016/j.jacc.2018.09.085, indexed in Pubmed: 30621952.

96. Combaret N, Gerbaud E, Dérimay F, et al. Collaborators. National French Registry of Spontaneous Coronary Artery Dissections: prevalence of fibromuscular dysplasia and genetic analyses. Eurolntervention. 2020 [Epub ahead of print]: EIJ-D-20-01046, doi: 10.4244/EIJ-D-20-01046, indexed in Pubmed: 33319763.

97. Verstraeten A, Perik MH, Baranowska AA, et al. Collaborators of the European/International Fibromuscular Dysplasia Registry and Initiative (FEIRI). Enrichment of rare variants in Loeys-Dietz syndrome genes in spontaneous coronary artery dissection but not in severe fibromuscular dysplasia. Circulation. 2020; 142(10): 1021-1024, doi: 10.1161/CIRCULATIONAHA.120.045946, indexed in Pubmed: 32897753.

98. Barthélémy $O$, Jobs A, Meliga E, et al. ESC Scientific Document Group. Questions and answers on workup diagnosis and risk stratification: a companion document of the 2020 ESC Guidelines for the management of acute coronary syndromes in patients presenting without persistent ST-segment elevation. Eur Heart J. 2021; 42(14): 1379-1386, doi: 10.1093/eurheartj/ehaa602, indexed in Pubmed: 32860030. 